\title{
A Study of Socialization of Children and Student-age Youth by the Express Diagnostics Methods
}

\author{
Magamed Nasib Ogly Samedov, Gennady Sergeevich Aikashev, \\ Viktor Yurjevich Shurygin, Aleksandr Vladimirovich Deryagin \\ and Il'mir Ahmetovich Sahabiev
}

Kazan Federal University, Elabuga Institute, Russia, Republic of Tatarstan, 423600, Elabuga, Kazan Street, 89

DOI: http://dx.doi.org/10.13005/bbra/1953

(Received: 16 July 2015; accepted: 25 September 2015)

\begin{abstract}
The article reveals the research methodology and describes approaches to study psychological and pedagogical level of socialization of children and student-age youth in Russia using advanced technological equipment. The authors carry out the analysis of the conventional and up-to-date methods of psycho-pedagogical investigation through the express diagnostics. One of these methods consists in the application of the diagnostic game designers, their integrated effect on the human body, based on measurement of physical and biological processes. The article describes experience in application of contemporary equipment for diagnostics of the social qualities of the people, as well as application features of technical devices, in particular "AR-101", "AR-600", and "Jibo" programmable microcontrollers of android family, and variety of medical, sporting, and household electronic game designers in the activity of pupils, students and educators. The authors consider in detail the design methods, the results of scientific research, and the technology of using several game designers in the express diagnostics.Based on the data, obtained during the study, the authors assess the socialization level of the students of supplementary education institutions, tested at the children's recreation camp "Intelletto", pupils of "Children's University" and "Entertaining Physics" and "Junior Programmer" teenage associations, as well as undergraduate students specializing in pedagogy at the Elabuga Institute of Kazan Federal University (EI KFU).
\end{abstract}

Keywords: Socialization of the person, psychological-pedagogical diagnostics, diagnostic equipment, game designer, educational institutions, professional training of the future teacher.

Today the need for psycho-pedagogical and technological support of the educational process involving children and students, as a factor of their socialization, becomes one of the main activity of teachers, educators, and mentors at all types of educational institutions in the Russian Federation. The same purpose is pursued by the implementation of the state concept

\footnotetext{
* To whom all correspondence should be addressed.
}

"Education development strategy in the Russian Federation up to 2025”.

One of the directions in implementation of this concept, encompassing the system not only of general but supplementary education, is the creation in Russia of innovative parks for children from 6 to 14 years old and older with a clear natural, technical, and computer focus (Education development strategy in the Russian Federation up to 2025, 2015).

It is known that the best of success in the educational process, and, consequently, the full- 
blooded life activity of the pupils in educational institution and outside, is achieved by only those teachers, who themselves possess a high degree of socialization in society. "Human socialization" can be considered as an aggregation of integrative qualities of a person, focused on interacting with other people in various scopes of activity, as well as the world around. In teacher's work, socialization can be considered as the basic competence of the teacher-educator towards the study of the socialization level of the younger generation with respect to themselves, other people, core subjects, school, and other society institutions (Andreeva, 2006).

Contemporary research methods of the socialization level include diagnostics of individual development of each student educated at school, and his mentors, as well as collection and processing of a variety of demographic data. Diagnostics also includes "non-public" information about the state of health, physical condition of the body, and the peculiarities of mental development of the individual (Romanova, 2008).

Naturally, the issues related to development of cognitive abilities of fledgling personality, his intelligence, features of the memory, attention, thinking, and imagination always will be in the range of vision of the teacher or the university lecturer. The teacher receives a huge portion of this kind of research data in the course of communication with his pupils in classes, during systematic observations, and analysis of life situations. Some information can be obtained using the capabilities of contemporary high-tech equipment and computer, operating in the express diagnostics mode.

For illustrative purposes consider a family robot-doll "Jibo", which is a loudspeaker system, equipped with an "electronic brain" (microcontroller). The device includes speakerphone, which provides two-way voice communication, motion sensors, two HD cameras and recognition systems, as well as a high resolution LCD touch screen. It supports $\mathrm{Wi}-\mathrm{Fi}$ and Bluetooth. A built-in microphone with $360^{\circ}$ coverage area allows one to talk with the robot even standing with the back turned to him being in the other end of the room (Baker, \& Skorenko, 2015).
Such high-tech devices of individual and group impact can be used not only for the development of social intercourse between the robot and humans, but also for research and educational purposes. This aspect is viewed in a number of research works by Russian authors, whose activity is built on the implementation of socialization concepts and humane approach to the pupil (Aikashev, Samedov, \& Shibanov, 2014; Samedov, Aikashev, Ushatikova, \& Minkin, 2015; Tsagareli, 2009; Computer system software “Comfort LOGO”, 2010).

\section{Methodology}

The Russian Federation has accumulated rich experience in socialization of the younger generation in terms of special studies on psychopedagogical diagnostics and social development of personality educated by a variety of means and technologies. In recent years, for these purposes, modern high-tech diagnostic equipment is being used in a variety of ways. These include also express diagnostic methods, which are based on the latest achievements of scientists in physics, biology, psychology, pedagogy, computer and information technologies, as well as computer science and engineering (Golubtsov, 2003; Osborne, 2013).

Conventionally, all the diagnostic methods can be divided into several classes, types and groups.

I. The first kind includes the "classic" types of diagnostic studies, which are conventional psychological and social researches (based on the main instruments, such as an interview, observation, and application of a certain kind of equipment). This kind of studies is described in detail in the scientific literature, in particular, presented by A. Anastasi, S. Urbina and others (Anastasi, \& Urbina, 2009).

II. The second kind includes "innovative" types of social research. This concerns, above all, the application of a variety of diagnostic equipment, which includes electronic, information, and computer technology to assess the level of knowledge of educated students or other areas of psycho-pedagogical and social research (Tsagareli, 2009).

The main types of social diagnostics 
usually include the analysis of pupils' activity products, their feelings, experiences, needs, as well as various types of testing, written surveys, questionnaires, the cards filled in depending on interests, and fulfillment of tasks according to their occupational guidance.

Diagnostics also includes study of person's temper, imagination, and will. It concerns also the peculiarities of improving memory, thinking, intelligence and speech, as well as psychomotor measures of the persons under test. In this regard mathematical tools and statistical data processing are used widely. These includes filling in a variety of tables, plotting graphs and charts, later used to analyze social development of personality and learning community, and to give the forecast of their further development (Romanov, 2008).

Naturally, the results of continuous systemic long-lasting work are influenced by many factors. First of all, note the fact that the socialization level of molded personality reflects conditions of both family and school (university) learning and education, as well as the nature of the attitude of the society to the younger generation. It is necessary to consider the interaction of a young person with religious communities, children and youth associations. Ultimately, the level of socialization of the younger generation is affected by the political and economic situation in the country and the society, relations with other countries and nations, the attitude of mass communication to the younger generation.

Moreover, according to the analysis of psycho-pedagogical scientific literature, the concept of "human socialization" can be considered in several methodological aspects.

Firstly, this is a biological factor, and, therefore, a factor of continuous personal development, which covers person's whole life, from his birth to death.

Secondly, this is a result of practical (primarily social) activity of a human, associated with the living in the native family, the quality of learning and education, received at the educational institutions.

Thirdly, this is a reflection of the level of well-being and financial status of a family, as well as average life span of loved ones and their health condition.
Fourthly, socialization can be regarded as a system of cultural and moral values of the individual, which includes the formation of moral concepts, beliefs, judgments, feelings, experiences, skills and habits that comply with the rules of the human conduct within a community in which individual lives and develops.

Diagnostics of social evolution of the younger generation may include, on the one hand, the identification of the development level (status) of trainees and their personal qualities, while on the other hand, reflect all the multidimensionality of personal traits. This may be dependence on age, health status at the current time, number of lessons per day, time spent at educational institution, character and style of relationships with teachers and other trainees, type of school, its location, etc.

According to the Russian researchers, child, pupil, or a student of the lyceum, college or university is, first and foremost, independent, value-oriented personality possessing the art of living and molding in a democratic society with developing market economy together with other people.

Foreign researchers are usually more concerned with the problem of molding "the soul of a young Russian", his spirituality, the breadth and depth of his interests and patriotism, combined with unconventional thought processes and logic of actions, respect for representatives of other countries and nations, as well as for national and religious backgrounds, the diversity of languages spoken, and a leading unifying role of the Russian language and literature.

Exactly in this case the principles of tolerance and the extent and depth of their expression may serve indicators of value navigators and social qualities of molded personality, better known to foreign researchers (Paternity: Upbringing, education, family, and culture, 2015).

Naturally, the implementation of the principles of tolerance, psychological and social skills of young people needs the efforts of the whole society and the state, including parents, relatives, teachers, friends and mates, as well as leaders of political and religious parties. All of these personality molding social institutions and socialization agents must advocate for nonviolence, obedience to laws, traditions and customs of the human society, the adoption of 
another, who may be distinct on different grounds.

A special group of innovative methods and technologies to investigate the level of socialization of children and student-age youth consists of a psychological diagnostics, which allow to some extent identifying and assessing the improvement of qualities, such as will, feelings, intelligence and other personality traits, using contemporary computer and technological equipment. Different controllers and microcontrollers make up the main components of such equipment (Golubtsov, 2003).

In practice, the main functions of the microcontrollers include the control and management of production processes, appliances, machinery, diagnostic equipment, systems for information acquisition, storage, and processing, as well as printers, faxes, cell phones and other devices (Novikov, 2012).

The first high-tech devices, emerged on the international market, were Stellaris ${ }^{\circledR}$ microcontrollers based on the core of the ARM ${ }^{\circledR}$ Cortex $^{\mathrm{TM}}-\mathrm{M}$ processor. The latest series of the Stellaris ${ }^{\circledR}$ LM4F of Texas Instruments is the next step on the path of their advancement. Software of MCU Stellaris Ware microcontrollers provides access to all peripheral units available on EK LM4F120XL board. It includes Stellaris ${ }^{\circledR}$ Peripheral Driver Library, which allows enough simple use of all the peripheral modules available on the microcontroller. Due to the large number of examples that reveal all the subtleties of working with this type of microcontroller, the user, including students, can implement their own solutions within the shortest time (Schonfelder, \& Schneider, 2012).

This type of controllers is widely applied in various portable devices and slot machines, household appliances, control devices, educational toys for kids, and diagnostic equipment. In addition, they are used as a basis for a variety of model kits of training equipment, such as "microcontrollers and microprocessor technology" for the institutions of vocational and higher education (Laboratory practicum guide, 2013).

In recent years, robotic toys called "androids" are being increasingly implemented in primary, general, and secondary education, as well as in education of students at pedagogical educational institutions. These include Russian robot models: AR-100, AR-101, AR-101M, and AR600; Japanese: Kondo KHR 2, Robovie M3; Korean: Robotis Bioloib, Robonova-1, and others. For the past 5-6 years, many Russian educational institutions have got their own population of "androids", or plan to start using them in the learning process in the near future (Young Scientist, 2015).

In terms of performance specifications, "androids" refer to the programmable diagnostic designers. They have, "head, hands, and feet", which are driven by a broad variety of motors and gears. They also have the analogues of "heart and brain”, which is programmed microchip or a programmable microcontroller. An equally important advantage of these kinds of designers is the high degree of freedom of their mechanical parts.

Among the main disadvantages of the simplest kind of "androids", one can note the problems arising when replacing some modules, for example, one "head" to another. Disadvantages include also the impossibility to sustain even a simple "dialogue", perform "verbal" commands that significantly reduces their functionality for the learning, educational and diagnostic purposes. Thus, for example, as a diagnostic element, "Android" of the AR-101 series with relatively small dimensions, no more than 10 inches, is used only for a mechanical assessment of the students' knowledge level, their abilities and skills in the basics of informatics.

Another development avenue of robotics in Russia and some other countries is related to the introduction into the mass production of fullsize (humanlike) android robots of AR-600 series (2009). There are more advanced counterparts, which are based on up-to-date hardware, software, and microcontrollers, such as, in particular MK-70 (android-robotics.com, 292015).

Introduction into the educational process of a humanlike "androids" allows one to eliminate many problems of their miniature counterparts on artificial intelligence. In particular, their "full size" (height not less than $1.4 \mathrm{~m}$ ), a unique voice interface that facilitates the exchange of information, allow inquisitive students not only to develop the software coding skills, but also to investigate the performance of a variety of social functions, such as maintaining dialogue between human and 
machine, as well as the performance of diverse commands.

The only obstacle for the mass acquisition of these comprehensive diagnostic designers is their high cost, which can reach several tens or even hundreds of thousands dollars.

The pedagogical staff of educational institutions can provide effective assistance in organizing a broad variety of lessons with pupils or students, both academically and in extracurricular time. Experience shows that children and students of all ages take an active part in the organization of various games, competitions in robotics, and the basics of software coding that gives the school psychologist and other specialists a wealth of information about the level of pupils' social development, their intellectual output and professional interests.

Such work can be performed successfully not only at schools, secondary or higher educational institutions, and supplementary education institutions, but also in specialized research laboratories, training centers and innovative polices. Thus, in recent years near the city of Kazan (Russia, the Republic of Tatarstan) a new science city (called Naukograd) was established to further develop IT-technologies in various fields of knowledge, the development of domestic software and its wide implementation in various spheres of national economy and defense industry.

The creation of such a research centre with a strong industrial and scientific base attracts not only Russian talented young people, but also professionals from other countries. This is provided by a high level of comfort for scientific research and creative work, good living conditions in a comfortable residential complex, as well as by a number of other conditions. A special role is played by economic factors, for example, offices for young professionals will be rented at a cost 100 times lower than their market price.

It is also important to note that such factors may determine the choice of contemporary express diagnostic technologies, whose main feature is a substantial reduction in the research time without losing all other important social dimensions. At that, among the main priorities or "innovations", in addition to the technical component, one can highlight advantages, such as the mass application, depth and speed of conducting research procedures, their high precision and safety, as well as individual and group approach.

For the implementation of all abovementioned endeavors we must not only use more deeply various advanced technologies, methods, techniques and tools of psychologicalpedagogical diagnostics, but employ various types of diagnostic equipment as widely as possible. This equipment can be arranged into the following major groups.

The first group consists of "high-tech diagnostic equipment" for medical and technical purposes. Its operation is based on the ideas of using a broad database generated by different devices and computer-based hardware-software package.

This group includes contemporary hightech equipment employed by various research institutes, industrial enterprises, medical centers, offices, and laboratories. At the heart of most of these devices are physical phenomena related to the effects of high and low frequency currents, electromagnetic field, ultrasound and acoustic waves directed on the object under test, including the human body.

An example is "MPI diagnostics" allowing one to assess the condition of internal organs and the entire human body (Young Scientist, 2015). This group includes also the medical diagnostic devices "Metatron”, “Omega M", "Lotus”, "LifeLine”, “Onix”, "IPAR”, "Olmag 1 and 2”, and others.

The second group includes industrial diagnostic equipment and household appliances with different kinds of sensors and digital controllers.

The range of such equipment is widely represented on the market of several countries. It is designed to organize physical training and sports of various categories of population, and includes children and adult sports complexes, such as stationary rowers, weight benches, versatile training systems, and other types of exercisers. This group includes also technological skill acquisition equipment, which is widely used when training to drive different types of ground, water and air vehicles. Training on computer simulators, the models, the sets of modern training equipment allows one to reduce significantly the time spent 
on training of future specialist, as well as to enrich the content, forms and methods of educational process organization (Paternity: Upbringing, education, family, and culture, 2015; High-tech medical equipment, 2015; Typical features of “Tokareva's heroine” (based on Victoria Tokareva's creative work), 2015; Scarlett floor scales SC-2216, 2015; Diagnostic instruments: Oberon, Metatron, Sensitive Imago, 2015; Immortality or death, 2015; Android Robots, 2015).

Operation of these devices is based on the laws of physics, radio engineering, biology, computer science and discrete mathematics, information technology, social sciences and humanities, as well as on the basis of social (health) and anti-aging medicine, psychology and pedagogy. This fact allows the developers of such diagnostic devices to claim that their products are used for a comprehensive high-tech survey of the human body (Schonfelder, \& Schneider, 2012).

The third group includes a variety of diagnostic equipment and instruments of psychoeducational and social purposes with biological feedback.

This group may include, for example, diagnostic devices "Activaciometer-AC-9K (Tsagareli, 2009) and “Comfort LOGO” (Comfort LOGO computer system software, 2010). They can be used not only to diagnose but also, in some cases, to develop physical, physiological, and mental statuses, to assess the most important personality qualities and traits.

Experience shows that using a broad software media of the above-mentioned diagnostic devices, each of the participants of diagnostic test may for a certain period of time acquire the skills to control their psychological and physical conditions. Besides, most contemporary instruments have training mode sessions that help to transfer acquired knowledge, abilities and skills into various forms of social and practical activity, whether it is studying, socializing or everyday life. These instruments can be used in a great number of universities of the Russian Federation, as well as in pre-school and non-school institutions, and applied to extend the theoretical and methodological bases of teachers' research work (Tsagareli, 2009).

It should be noted that the main innovative component in the use of high-tech diagnostic equipment is the fact that the researcher, whether the psychologist, teacher, doctor or the patient himself has the visual ability to track on the monitor screen the nature of the studied processes, including the condition of the body or certain organs. All the received information is retained for a long time. It can be transferred via a closed and secure communication channels to other experts, persons concerned, for example, children' parents, experts of medical or social agencies for operational impact on the condition, treatment, social behavior of the patient or the observed person.

All this improves the quality of social research to identify specific manifestations of emotional, psycho-motor, physiological, pedagogical, and even moral qualities of both a single person or a group of students, as well as the whole children' or student' group for their further enhancement in a social environment (High-tech medical equipment, 2015).

Naturally, the scope and the quality of diagnostic work with pupils or students in an educational institution, unlike industrial enterprises, rests entirely on professionals with pedagogical education. Typically, such work is organized under the guidance of the experienced school or university psychologists, teachers of specialized departments, faculties or institutes, which ensure the efficiency (Andreev, 2006).

The analysis of the citizens' interests in industrialized countries towards contemporary measuring and diagnostic equipment, used at home, suggests that in the near future industrial enterprises will greatly increase the production of advanced high-tech devices with broad operation spectrum for different purposes (High-tech medical equipment, 2015; Typical features of “Tokareva's heroine" (based on Victoria Tokareva's creative work), 2015; Scarlett SC-2216 floor scales, 2015; Diagnostic instruments: Oberon, Metatron, Sensitive Imago, 2015; Immortality or death, 2015; Android Robots, 2015).

As an example, we can mention a household appliance called "Scarlett diagnostic scales" made in China. It can be used to monitor the human's weight change, calculate his daily norm of calories, consumed from food, monitor the effectiveness of the diet, as well as determine the percentage of fat, water, muscle and bone mass. This instrument, according to its developers, is 
working on the principles of the analysis of bioelectrical resistance; at that the percentage composition of various tissues is determined just in a few seconds (Scarlett floor scales SC-2216, 2015).

The fourth group includes the devices, which use "ART" and "IT" computer technologies for the study of latent (hidden) psychological, pedagogical, social and medical qualities of a person (High-tech medical equipment, 2015; Diagnostic instruments: Oberon, Metatron, Sensitive Imago, 2015; Android Robots, 2015), as well as assessing the quality of acquired knowledge.

\section{This includes the following}

a) Visual and computer evaluation of the drawing tests results, including both conventional options (using charcoal, pencils, markers, and paints) and advanced drawing techniques (using colored sand, streams of air through the tubes of colored paints);

b) 3D computer modeling and design, including origami, art design, color appliqué, exercises with plastic transformer designers, etc.;

c) Educational and psychological testing, evaluation of learning based on computer tests, conducting tests for teachers on school and university disciplines.

This group includes also the equipment used in organization of the basic and the common state examinations (in Russian OGE and EGE), the Federal exam on professional education (FEPA) and other forms of state assessment of the knowledge level.

The fifth group includes diagnostic equipment based on the technology of pedagogical (didactic) games for the brain or so called IQ-Toys from around the world (IQ-Toys, 2014).

These devices include "speaking" and musical toys, puzzles, paper and plastic type designers, LEGO type designers, controlled cyberbots, model cars, dolls, soft toys and other educational playthings. They are in great demand on the market of mass consumption goods and services. However, their inappropriate use by children and adolescents may also lead to negative consequences.
Among the positive factors we can mention their wide application in correctional and pedagogical practices with a certain category of children and adolescents. First of all, these are children with various disabilities of speech, physical, mental and spiritual development.

Among the negative effects of programmable electronic toys, as by the way, many kinds of modern gadgets, we may note a highgrade focusing illusion in children and student-age youth, which can be reduced only in the course of purposeful educational work on the part of teachers, educators and children’ parents.

\section{RESULTS}

In our opinion, the diagnostic game designers may be of particular interest to the teacher-researcher. This game designer can be created not only by university professors, but also school teachers, and even students during their spare time. We carry out this work in "Young physicist" and "Young programmer" circles classes at the summer recreation camp "Intelletto" organized at EI KFU, as well as in the school laboratory "Scythians" and summer physical and mathematical school in Elabuga city.

Technical content of diagnostic game designers can be the most diverse. Typically, it includes a hidden wiring detector, microammeter, copper and galvanized plates, stop-watch timer, compass, temperature and air humidity sensors. In addition, the diagnostic game designer may include switches, LEDs, and elements of solar or battery driven charging devices.

The content of children's game designer must also be very diverse. It may include different elements of 3D or 2D toys, parts or whole structures of electrified, computer, musical games and entertainments of domestic or foreign production, and much more.

Assembled in a single design (portable case) and provided with detailed technical, methodological and technological support, all of this material acquires its new quality. It becomes a diagnostic tool, which can be employed to explore the evident or hidden potential of a person, whether a small child, pupil or student of a higher educational institution.

In our opinion, a certain innovative trend 
in diagnostic techniques could be the development and implementation of diagnostic and homebuilt game designers into education/bringing-up process. We started this work in the mid 90-ies of the XX century on the basis of school research laboratory of the creative association "Scythians" and continue it until now. Over these years we have created the designers, such as "Bioenergometer", "Happy frogs", "Yin-Yang”, "Lucky chance", and many others.

One of such devices is the game diagnostic designer "Yin-Yang" or "Success matrix", created in 2011 on the basis of "three in one" family game "Buz..." for the children aged 5+, produced by People's Republic of China.

The main research task, when using this diagnostic designer at social-pedagogical investigations, was the desire to identify within a short period of time the level of tolerance among people of different age groups during their joint activities.

Participation in diagnostic game was carried out individually, in pairs, triplets and other small groups of people on a voluntary entertainment and competitive basis, expressed by test organizers in oral or written form. At that, test organizers have considered the level of education, individual psychological qualities, and life aspirations of the test persons, though this did not play a decisive role.

As shown by our many years experience, the most significant socio-diagnostic effect when applying a game designer is obtained in the case where at least two players were involved simultaneously. These could be family couples, children and their parents, friends and acquaintances, schoolmates or classmates. It is desirable to have representatives of different age groups and (or) gender, for example, a boy and a girl, a dad and a daughter, a mom and a son, teeners of the opposite sex, etc.

Like all previous diagnostic designers, this device is a portable unit (assembled by us inside a small suitcase), composed of several electronic toys of Chinese and Russian production. It runs on 3 to 12 volts DC batteries (depending on design elements) and is completely safe for the life and health of the game players.

In addition to the research and diagnostic functions, the organizers of the game set specific goals and objectives to all participants. Thus, for example, the following task was given to players as a social attitude: to "pass" 3D obstacle most correctly and accurately during a certain period of time using a special detector, ensuring the fewest mistakes (touchings) that reflects the level of "compatibility" and tolerance between the members of tested group.

It was established through the research and trial that the time records of the participants, involved in the express diagnostics, largely depended on their age. Thus, for students and pupils these records ranged from 20 to 35 seconds, whereas for people of middle or advanced age the records varied from 45 to 60 seconds per passing each 3D obstacle.

According to the established rules and the personal interests of participants, identified empirically in the course of conducted tests, the players were asked to pass one to three types of 3D obstacles, namely "Stroke of luck", "Tree of life" and "Hour of triumph" in the course of one express diagnostic session. At that, the time needed to pass the obstacles was measured with an electronic stopwatch. The number of mistakes (touchings) were recorded visually and aurally (by sound signal), as well as by means of electronic scoreboard. In our case, originally we have used non-programmable calculator (operating in the mode of $1 ;+;=")$, whereas later we employed a programmable digital controller and a video recorder providing subsequent analysis and reflection (at the request of game participants) of the received data on a personal computer.

It is important to note that the video recording during diagnostic express testing was conducted in an open mode. It can be arranged not only in educational institutions, but also in the institutions of supplementary education, as well as during the spare time. Naturally, all participants of this stage of diagnostic game (including adult mentors) should be warned in advance in writing or orally about video recording.

The results of express diagnostics were interpreted as follows.

1) Zero touchings. This usually means the need for double checking of the game designer performance.

2) Just one touching in each of the three tests means that the level of "tolerance" is very 
high. In this case, we can congratulate the participants with their first winning and declare that if they will show the same results in the next 3-4 days, they will face a welldeserved prize.

3) The number of touchings in each of three tests from 2 to 5 shows that the level of "tolerance" is quite high. We suggest players to consider, how they could use their capabilities with higher benefits for themselves and their loved ones.

4) The number of touchings in each test from 6 to 10 corresponds to the average level of "tolerance". In this case participants are suggested to increase the communication time with interesting people, develop their personal capabilities, such as love and care to their friends and relatives, as well as to train coordination and control of their own emotional state. Also tasks were given to improve key personality traits, such as working capacity, stronger work ethic in learning performance and day-to-day life.

5) The number of touchings in each test from 11 to 15 indicates low level of "tolerance". To substantially improve the results in such creative tests we can recommend one to deal with interesting work and study, rational interests, socialize with family and friends during outdoor recreation.

6) The number of touchings in each test from 16 to 25 or even more testifies that most likely the day was not the best one for the participants. Perhaps, they have already had to overcome some obstacles and severities. One may suggest them to overcome each of hardships honorably, to strengthen relationships with loved ones, relatives, friends and acquaintances that in the near future will lead to better results in this game.

Based on development of methodological bases for implementation of diagnostic game designers in the context of school and university laboratories, which are presented in authors' works (Aikashev, Samedov, \& Shibanov, 2014; Samedov, Aikashev, Ushatikova, \& Minkin, 2015; Tsagareli, 2009; Education development strategy in the Russian Federation up to 2025, 2015), we have seen the following.

Firstly, the application of game diagnostic techniques, when working with children of different age groups, leads only to positive results. In particular, significantly increases motivation and interest in upcoming academic studies at school or at the university. This was revealed in the course of our research, which involved over 250 children and over 700 students. Moreover, younger and middle-aged children in $70 \%$ of cases reinforce the material learnt during the classes and extracurricular activities, and fall into created favorable conditions to form their life values (85\%). High level of tolerance (89-90\%) was detected in the majority of our research participants, whereas the gradations of the fundamentals of communicative culture, creative imagination and speech sometimes reached $75-95 \%$.

Secondly, the use of diagnostic game designers does not cause psychological rejection in the children of different age groups and studentage youth, as well as their parents, teachers, educators, and other categories of population. Thus, according to the results of studies conducted in 2011-2014, which were attended by 350 people, positive attitude towards the implementation of diagnostic game designers and relevant psychological and pedagogical technologies in work with children and adolescents was expressed by 343 people (Samedov, Aikashev, Ushatikova, \& Minkin, 2015). A similar result was obtained in studies conducted from 2007 to 2015, which were attended by over 1,500 people, ordinary citizens of the Elabuga city (the Republic of Tatarstan) during the celebration of national and state holidays "Sabantuy", "City Day”, "National Unity Day", and others.

In all these cases, the percentage of the adult population, who expressed doubts concerning the application of diagnostic game designers, did not exceed 2-3\% that means a strong confidence to the data obtained in the course of the game express diagnostics. The same results have led from the analysis of written survey of students of pedagogical specialties at EI KFU.

Thirdly, the design, development and application of diagnostic game designers once again convinced us that their urgent industrial implementation hide a huge scientific research, technical, and creative potential not only for children and student-age youth, but also for teachers and mentors, as well as scientists, 
engineers, software engineers and designers.

\section{DISCUSSION}

Today's practice shows that tech-based (innovative) express diagnostics can significantly reduce the time to study socialization manifestations, such as the depth of interpersonal relations of the child with his peers and teachers, as well as the level of tolerance in relationships between children in even-aged or uneven-aged groups. There is a clear relationship between the level of cohesion of children (students) group and the gradations of social relations, for example, molding their own opinions.

Thus, socialization of an individual can be understood as a combination of universal competencies of the future citizen in a society with favorable conditions, intended to implement all of his capabilities. These include the cultivation of value navigators from the older to the younger generation pursuant to their age or social status, not only in learning circles, but also in creative teams and communities. This may be class, affinity group, club, student group, students' parents and other associations of people. Their activities and social qualities, to a greater or lesser degree, also can be investigated using contemporary express diagnostic instruments.

Given that the socialization of the individual in a society with developed market economy, in some ways, is similar to the concept of "tolerance", its main purpose is to generate respect, acceptance and appreciation of the rich diversity of our world's cultures, forms of selfactualization, and the ways of expressing own individuality (Samedov, Aikashev, Ushatikova, \& Minkin, 2015).

That is why the study of the level of children' and students' socialization, as a factor of a deep, comprehensive, harmonious molding of personality, which are based on various technologies of psycho-pedagogical and technical diagnostics, should become essential tools of the contemporary educational process.

In this regard, the diagnostics of individual's socialization can and should become a powerful factor in person's mental development and the formation of the most important traits, qualities and features of character. It should include an assessment of cognitive and analytical capabilities of students towards learning the diversity of the world, educational material, forecasting the success of training and personal enhancement in any educational institution and beyond.

In addition, the study of socialization should be based on the various activities undertaken by individual in the course of relationships with other people. Therefore, diagnostics of interpersonal relations, built on the principles of tolerance, humanism and democratic freedoms, as enshrined in various international and national legislative documents, can and should become the basis to form practical knowledge, skills and abilities of each person that are needed him in everyday life, as well as in the subsequent years of professional activity. Besides, in course of time, acquired social skills become the basis for the development of personal competences in the implementation of various forms of interaction with other people, regardless of their nationality, sex, religion, skin color, language and other national peculiarities.

Another field of activities of educational institutions employees in Russia, associated with the study and molding of personality's social traits and level of socialization in society, is focused at preventing educational abandonment of children, pupils or particular groups of student-age youth. The core of such work usually consists of corrective training, assistance from the counselor and the school psychologist, as well as the study of children's personality traits, their education at school and in family. The same objective should be pursued by any kind of class hours on the basis of correctional work with troubled children and the children with disabilities, as well as a work on vocational guidance of pupils (Anastasi, \& Urbina, 2009).

In addition, the investigation and molding of socialization level, as a system of the most important personality qualities under the teacher's guidance, can be linked to provision of various types of assistance to children and certain categories of student-age youth in crisis situations. This is prevention of suicidal and aggressive intentions, ruefulness, depression, or Internet addiction. 


\section{CONCLUSION}

The analysis of psychological, pedagogical and scientific-technical literature shows that diagnostic game designers (irrespective of their functional and technical capabilities) refer to "motivation-meter" type instruments. In our opinion, this name can be given to all diagnostic instruments, which can be used to measure the level of motivation, as well as mental, psychological, pedagogical and social qualities of the individual, where the teacher's work includes the organization of professional and systematic “express testing” (Samedov, Aikashev, Richter, \& Rieckmann, 2014).

According to experts of several countries, the main objective of all such researches consists in assisting young people to understand themselves, other people (Osborne, 2013), the world, and the society in general (Zohar, 2013) that provides more close relationship and interdependence of technical (Rutten, van Joolingen, \& van der Veen, 2012), technological (Barth, Adomâent, Fischer, Richter, \& Rieckmann, 2014), and social (Kaptan, \& Timurlenk, 2012) assurance of educational process, aimed at the development of creative potential of a personality and the formation of tolerance among various categories of the population (UN Resolution on International Year for Tolerance, No 5.61, 1995).

A retrospective analysis of the Russian periodicals shows that the system of socially important principles (humane treatment of educated personality, development of interest, voluntary participation, etc.) is not just declared, but implemented in practice. This involves also psycho-pedagogical, social, and diagnostic work with children, adolescents, and young adults (Survey of journals “Psychology Issues” for 20112015, 2015).

As shows experience, the main point should be the implementation of a human values system: motive-incentive-effect-reward. For the child, the approval and praise for participation in the game, the satisfaction of his natural curiosity, imitation of the elder (e.g., the teacher), and much more serves the motives, incentives and rewards. In our opinion, especially valuable are situations, where diagnostic work leads to enrichment of any child with practical experience, development of his communicative skills in cooperation with other people, initiates the interest to himself and the social qualities of the individual. This can be seen as the result of the whole innovation process, though not only as a sphere of play activities.

Naturally, the teacher-researcher carefully observes the activities of the educated children, making special entries in his notebook or journal. With the consent of parents and children, the whole game diagnostic process can be recorded with a video camera, cell phone or web-camera for further review or follow-up theoretical and practical research. Various educational conversations, additional educational sessions, oral, written surveys, and much more could be organized much easier based on the obtained information and the interest shown by children towards one or another diagnostic game and its results, as well as towards the teacher (regardless of children's ages).

Finally, the information obtained allows us to carry out a detailed analysis of the work conducted during a certain period of time (reflection), to make diagnostic tables, to built pie and bar charts, to encourage the most active participants, their assistants, to plan and implement new avenues for the advancement of studies, educational and diagnostic work with the younger generation.

\section{ACKNOWLEDGEMENTS}

The work is performed according to the Russian Government Program on Competitive Growth of Kazan Federal University.

\section{REFERENCES}

1. Aikashev, G., Samedov, M., \& Shibanov, V., Research laboratory in Russian education: Experience and prospects. Middle-East Journal of Scientific Research 2014; 20(11): 1339-1343.

2. Anastasi, A., \& Urbina, S., Psychological testing (7th ed.). Saint Petersburg: Piter, 2009.

3. Andreev, V., Pedagogy of higher education. Innovative predictive course. Kazan, 2006.

4. Android robots., Retrieved June 17, 2015, from http://android-robotics.com, 2015.

5. Baker, B., \& Skorenko, N., Inexhaustible energy of Jeffrey Lieberman. Popular Mechanics, 2015; 3(149), 120-125.

6. Barth, M., Adombent, M., Fischer, D., Richter, 
S., \& Rieckmann, M., Learning to change universities from within: a service-learning perspective on promoting sustainable consumption in higher education. Journal of Cleaner Production, 2014; 62(1), 72-81.

7. Comfort LOGO computer system software., User Manual.St.-Petersburg: JSC “NPF Amatea”, 2010.

8. Diagnostic instruments: Oberon, Metatron, Sensitive Imago., Retrieved March 10, 2015, from www./sensitive-imago.ru /118 eguipment.html., 2013

9. Education development strategy in the Russian Federation up to 2025. Retrieved March 19, 2015, from http://bda-expert.ru/doc/2015-01-14strategiya-razvitiya-vospitaniya-rf-proekt.zip.

10. Golubtsov, S., The FVR microprocessors: from simple to complex. Moscow: SOLON-Press, 2003.

11. High-tech medical equipment. Retrieved February 24, 2015, from http://rtmedintegrator.ru/vysokotekhnologichnoemeditsinskoe-oborudovanie/.

12. Immortality or death., Retrieved April 21, 2015, from http://bessmertie.by/index.siles/ Page2207.htm, 2015.

13. Kaptan, K., \& Timurlenk, O., Challenges for science education. Social and Behavioral Sciences, 2012; 51: 763-771.

14. Microcontrollers and microprocessor technology. Laboratory practicum guide. Moscow: OOO "Profbasa".

15. Novikov, Y., \& Skorobogatov, P., Fundamentals of microprocessor technology. Moscow: BINOM. LZ, INTUIT, 2012.

16. Osborne, J., The 21st century challenge for science education: Assessing scientific reasoning. Thinking Skills and Creativity, 2013; 10: 265279.

17. Paternity: Upbringing, education, family, and culture. Retrieved January 20, 2015, from http:/ /www.otcovstvo.info/mezhdunaronyiy-dentolerantnosti/.

18. IQ-toys. Retrieved October 21, 2014, from trk- parus.ru.

19. Romanova, E., Psychological diagnostics. Training Manual (2nd ed.). St.-Petersburg: Peter, 2008.

20. Rutten, N., van Joolingen, W., \& van der Veen, J., The learning effects of computer simulations in science education. Computers \& Education, 2012; 58(1): 136-153.

21. Samedov, M., Aikashev, G., Ushatikova, I., \& Minkin, A., Commercially available diagnostic device used in educational process: Experience and innovation. Biosciences Biotechnology Research Asia, 2015; 12(1): 531-538.

22. Scarlett floor scales SC-2216., Retrieved April 22, 2015, from www.dns-shop.ru/catalog/ i171915/vesy-napolnye-scarlett-sc-2216, 2013.

23. Schonfelder, G., \& Schneider, K., Measuring devices based on ATmega microprocessor. St.Petersburg: BHI, 2012.

24. Shurygin, V., \& Deryagin, A., Development of technical abilities of gifted children in out-ofclass job. Problems of Modern Science and Education, 2. Retrieved October 21, 2014, from www.science-education.ru /108-8773, 2013.

25. Survey of journals "Psychology Issues" for 2011-2015. Retrieved March, 20, 2015, from www.voppsy.ru.

26. Tsagareli, A., System diagnostics of human and the development of mental functions: Kazan, 2009.

27. Typical features of “Tokareva's heroine” (based on Victoria Tokareva's creative work), 2015; Retrieved May 12, 2015, from www.moluch.ru/ archive/78.

28. UN Resolution No 5.61 on International Year for Tolerance. , Retrieved June 20, 2015, from http://http.herzen.spb.ru/img/files/stas/ tolerance/Deklaraciya_principov_tolerantnosti. pdf, 1995

29. Zohar, A., Challenges in wide scale implementation efforts to foster higher order thinking (HOT) in science education across a whole school system. Thinking Skills and Creativity, 2013; 10: 233-249. 